\title{
Study on horizontal vibration characteristics of high-speed elevator with airflow pressure disturbance and guiding system excitation
}

\author{
Jie Liu, Ruijun Zhang ${ }^{*}$, Qin He, and Qing Zhang \\ College of Mechanical and Electronic Engineering, Shandong Jianzhu University, 250101 Ji'nan, PR China
}

Received: 14 January 2018 / Accepted: 17 September 2018

\begin{abstract}
This paper aims to study the horizontal vibration dynamic characteristics of high-speed elevator by considering the combined effect of airflow and guiding system. The relationships of lateral force and overturning moment with horizontal displacement, deflection angle displacement and rated speed of the car are mathematically solved, and the horizontal vibration dynamic model of the car under the two excitations is established. For case model, the natural frequency and horizontal vibration response of the car are studied, and the guide-rail excitation frequency and car natural frequency are compared and analyzed. The results indicate that the higher the rated speed is, the more obvious the resonance phenomenon between the guide-rail and car will be in a certain range; the effect of airflow on horizontal vibration acceleration of the car with a speed lower than $6 \mathrm{~m} / \mathrm{s}$ is small, but when the speed is over $6 \mathrm{~m} / \mathrm{s}$, the airflow will greatly affect the single-peak value of horizontal vibration acceleration, which is approximately a quadratic relationship; the deflection angle displacement has an increasing influence on horizontal vibration dynamic response with the increasing speed. The conclusions provide a theoretical guidance for the research and control on the horizontal vibration of highspeed elevator.
\end{abstract}

Keywords: Horizontal vibration / high-speed elevator / airflow pressure disturbance / guiding system

\section{Introduction}

The high-rise and super high-rise buildings are constantly emerging, making the high-speed and large-travel become the inevitable trend of the development of the elevator. With the increase of elevator speed, the resulting horizontal vibration is becoming more and more intense, which has become an important factor affecting the ride comfort of the elevator [1]. The related literatures indicate that the response value of the horizontal vibration acceleration of the elevator is directly proportional to its running speed [2]. In addition, when the high-speed elevator is running at a high speed, the rapid compression of the airflow in the hoistway will cause strong transient pressure shock and tunnel inverse aerodynamic effect, which will further aggravate the horizontal vibration response. Strong horizontal vibration will not only reduce the lifespan of elevator, but also have a serious impact on its operation safety [3], which restrict the rapid development

\footnotetext{
* e-mail: zhangruijun@sdjzu.edu.cn
}

of the high-speed elevator. Therefore, it is very important to study the horizontal vibration characteristics of the elevator at high speed.

As a complex electromechanical system, the high-speed elevator has many causes for its horizontal vibration. Under normal conditions, the main causes of the horizontal vibration can be attributed to two types: the airflow pressure disturbance and the guiding system excitation [4]. The guiding system is mainly composed of the guide-rails and the guide-shoes, and the excitation generated by the guiding system mainly depends on the time-varying stiffness of the guide-rail (the periodic variation of the bending stiffness of the guide-rail in its height direction), the profile deviation and the installation error. Taking the rail unevenness as horizontal displacement excitation, Xia et al. [5] established a horizontal vibration model of the elevator car by considering the variation of real-time interfacial stiffness between the guide-rail and the guide-wheel, and studied the horizontal vibration characteristics of the elevator car. Transforming the factors such as rail roughness, rail bending, guide-shoe defect and so on to the contact force of the guide-rail to the guide-shoe and considering the excitation at rail joints, Yin et al. [6] studied the horizontal vibration dynamic characteristics of the multi-degree of freedom of the 
high-speed elevator. Mei et al. [7] fitted the irregularity excitation between the guide-roller and the guide-rail by considering the rail profile deviation and the roller roundness tolerance, and solved the horizontal vibration response of the high-speed traction elevator by using the numerical analysis method finally. Utsunomiya et al. [8] analyzed the vibration spectrum of the guide-rail, which indicated that the disturbance of the rail mainly concentrated in the lowfrequency areas, and there was a main disturbance frequency which was directly proportional to the running speed of the elevator and inversely proportional to the guide-rail length. Colón et al. [9] used Karhunen LoèVE and polynomial chaos method to study the dynamic characteristics and control of the horizontal vibration of elevator car caused by rail irregularity through the establishment of the irregular stochastic model of the rail profile.

The continuous improvement of elevator running speed will cause many complicated aerodynamic problems when the high-speed elevator car is running in the long hoistway. Therefore, the aerodynamic characteristics of high-speed and ultra-high-speed elevator have attracted wide attention from scholars at home and abroad in recent years, and they mainly focused on the test bench simulation experiments and numerical simulations. Based on the dimensionless analysis of parameters affecting the tunnel effect of high-speed elevator, Duan et al. [10] designed and constructed a simplified experimental equipment for aerodynamic characteristics of high-speed elevator, and then carried out the experimental simulations under different elevator conditions such as different blockage ratios and reserved ratios. Bai et al. [11] built a physical experiment model in a certain proportion to study the aerodynamic characteristics of super high-speed elevator, measured the instantaneous speed of a falling elevator car at five distinct positions as well as the average pressure in front of and behind the car along the hoistway, and finally introduced a new concept of "tunnel effected shape drag". Wang et al. [12] simulated the three-dimensional turbulent flow of high-speed elevator using the static uncompressible Navier-Stokes equations, studied the aerodynamic characteristics of elevators with different blockage ratios, and obtained the conclusion that pressure and drag forces of the high-speed elevator are positively related to the blocking ratio. In order to optimize the aerodynamic characteristics of high-speed elevator and find a reasonable flow-guiding cover for the elevator car, $\mathrm{Li}$ et al. [13] simulated and optimized a high-speed elevator with loading capacity of $1000 \mathrm{~kg}$ and speed of $6 \mathrm{~m} / \mathrm{s}$ by CFD. Shi et al. [14] conducted dynamic simulations of high-speed elevator using two-dimensional model, and studied the transient changes of the aerodynamic forces acting on the car before and after the interlacing of counterweight and elevator car. Chen et al. [15] compared and analyzed the models of 2Dhoistway, 3D-hoistway and 3D-hoistway with landing sill through ANSYS, and studied the aerodynamic characteristics of the hoistway flow field finally.

Although the above studies of the effects of airflow pressure disturbance and guiding system excitation on horizontal vibration characteristics of high-speed elevator have taken substantive results, the aerodynamic characteristics of hoistway flow field and mechanical characteristics of the car under this effect are mainly concentrated when studying the influence of the airflow pressure, few scholars applied the airflow influence to study the dynamic characteristics of elevator horizontal vibration, and they took little consideration of the combined effect of airflow pressure disturbance and guiding system excitation. In addition, due to the limitation of computational conditions, the two-dimensional physical model was taken as the research object in the analysis of the airflow pressure within the hoistway usually, and the influence of the horizontal displacement of the elevator car was not taken into consideration, which ignored the essential features of the high-speed elevator.

In view of the above problems, this paper considers the combined effect of airflow pressure disturbance and guiding system excitation, establishes a 3-D calculation model of high-speed elevator system, and simulate the model to solve the numerical relationships between the aerodynamic forces/moments and the horizontal displacement and deflection angle displacement of the car using FLUENT by analyzing the flow field characteristics, which is used as the input of the airflow pressure disturbance, and uses the guide-rail bending deformation as the input of guiding system excitation, establishes a horizontal vibration dynamics model of high-speed elevator based on the airflow pressure disturbance and guiding system excitation, then solves the dynamic model using the Newmarkbeta method, and finally compares and analyses the natural frequency and horizontal vibration dynamic response of the high-speed elevator car with or without considering the airflow pressure disturbance with an case model, respectively.

\section{Analysis of the airflow pressure disturbance within the hoistway}

\subsection{Mathematical model of 3D flow field within the hoistway}

\subsubsection{Governing equations of flow field within the hoistway}

During the normal operation of high-speed elevator, the airflow in the hoistway presents a flow state of low Mach number $(\mathrm{Ma}<0.3)$ and high Reynolds number $(\operatorname{Re}>2320)$, which can be regarded as the turbulent flow of incompressible gas [13]. Regardless of energy exchange, in the Cartesian coordinate system $(x, y, z)$, the governing equations that describe the flow filed are the incompressible Navier-Stokes equations, i.e., the mass conservation equation and the momentum conservation equations.

The mass conservation equation:

$$
\operatorname{div}(\boldsymbol{U})=0
$$

The momentum conservation equations:

$$
\begin{aligned}
& \frac{\partial u_{a}}{\partial t}+\operatorname{div}\left(u_{a} \boldsymbol{U}\right)=\operatorname{div}\left(\operatorname{vgrad} u_{a}\right)-\frac{1}{\rho} \frac{\partial p}{\partial x} \\
& \frac{\partial v_{a}}{\partial t}+\operatorname{div}\left(v_{a} \boldsymbol{U}\right)=\operatorname{div}\left(\operatorname{vgrad} v_{a}\right)-\frac{1}{\rho} \frac{\partial p}{\partial y}
\end{aligned}
$$




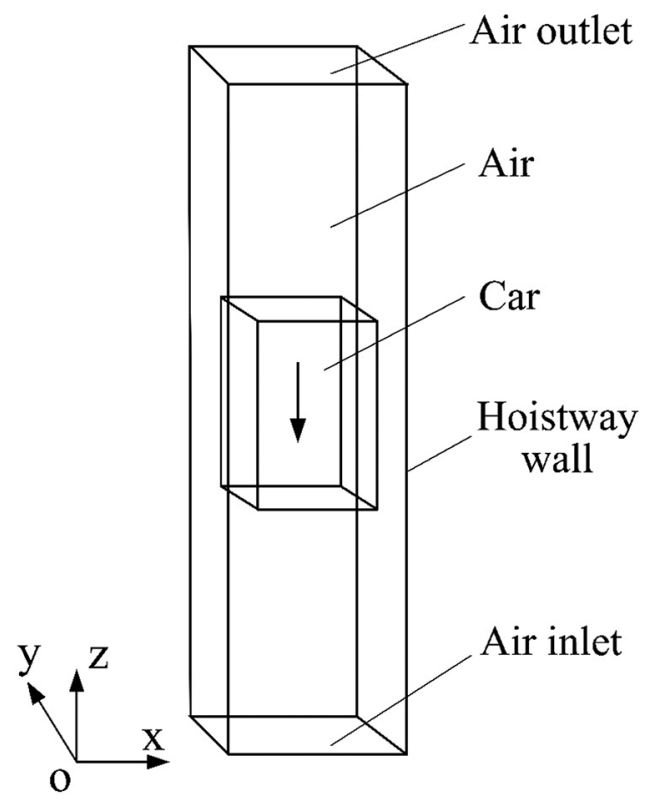

Fig. 1. Calculation model of high-speed elevator system.

$$
\frac{\partial w_{a}}{\partial t}+\operatorname{div}\left(w_{a} \boldsymbol{U}\right)=\operatorname{div}\left(\operatorname{vgrad} w_{a}\right)-\frac{1}{\rho} \frac{\partial p}{\partial z}
$$

where $\boldsymbol{U}$ is air velocity vector, $u_{a}, v_{a}$ and $w_{a}$ are the velocity components of $\boldsymbol{U}$ in $\mathrm{x}, \mathrm{y}$ and $\mathrm{z}$ coordinate directions, $t$ is time, $\rho$ is air density, $v$ is air kinematic viscosity, $p$ is pressure, div is divergence, grad is gradient.

\subsubsection{Turbulence model}

A turbulence model is required for numerical simulation of the turbulent flow field. At present, the most widely used turbulent numerical simulation method in engineering is Reynolds Averaged Navier-Stokes (RANS). Its turbulent models mainly include mixed long model, one-equation model and standard two-equation model, and the application of standard two-equation model is the most common. Therefore, RANS and the standard two-equation model are used in this paper to simulate the flow field within the hoistway.

The turbulent kinetic energy $k$ equation:

$$
\frac{\partial k}{\partial t}+\operatorname{div}(k \boldsymbol{U})=\frac{1}{\rho} \operatorname{div}\left[\left(\mu+\frac{\mu_{t}}{\sigma_{k}}\right) \operatorname{grad} k\right]-\varepsilon+\frac{\mu_{t} P_{G}}{\rho}
$$

The turbulent dissipation rate $\varepsilon$ equation:

$$
\begin{aligned}
\frac{\partial \varepsilon}{\partial t}+\operatorname{div}(\varepsilon \boldsymbol{U})= & \frac{1}{\rho} \operatorname{div}\left[\left(\mu+\frac{\mu_{t}}{\sigma_{\varepsilon}}\right) \operatorname{grad} \varepsilon\right]-C_{2} \frac{\varepsilon^{2}}{k} \\
& +\frac{C_{1} \mu_{t} \varepsilon P_{G}}{\rho k}
\end{aligned}
$$

where $\mu$ is air dynamic viscosity, $\mu_{t}$ is turbulent viscosity coefficient and

$$
\begin{gathered}
\mu_{t}=\rho C_{\mu} \frac{k^{2}}{\varepsilon} \\
P_{G}=2\left[\left(\frac{\partial u_{a}}{\partial x}\right)^{2}+\left(\frac{\partial v_{a}}{\partial y}\right)^{2}+\left(\frac{\partial w_{a}}{\partial z}\right)^{2}\right] \\
+\left(\frac{\partial u_{a}}{\partial y}+\frac{\partial v_{a}}{\partial x}\right)^{2}+\left(\frac{\partial u_{a}}{\partial z}+\frac{\partial w_{a}}{\partial x}\right)^{2} \\
+\left(\frac{\partial v_{a}}{\partial z}+\frac{\partial w_{a}}{\partial y}\right)^{2}
\end{gathered}
$$

$C_{\mu}, C_{1}, C_{2}, \sigma_{k}, \sigma_{\varepsilon}$ are empirical constants, and $C_{\mu}=0.09$, $C_{1}=1.44, C_{2}=1.92, \sigma_{k}=1.0, \sigma_{k}=1.3$.

If $\varphi$ is introduced, then equations (1)-(6) can be written as the following general governing equation:

$$
\frac{\partial \varphi}{\partial t}+\operatorname{div}(\varphi \boldsymbol{U})=\frac{1}{\rho} \operatorname{div}\left(\Gamma_{\varphi} \operatorname{grad} \varphi\right)+\frac{1}{\rho} S_{\varphi}
$$

where $\varphi$ is generic variable (when $\varphi$ are $1,\left[u_{a}, v_{a}, w_{a}\right], k$ and $\varepsilon$, Eq. (8) represents the mass conservation equation, the momentum conservation equations, the turbulence kinetic energy $k$ equation and the turbulent dissipation rate $\varepsilon$ equation respectively), $\Gamma_{\varphi}$ is generalized diffusion coefficient, $S_{\varphi}$ is generalized source term.

\subsection{Numerical simulation and analysis of flow field within the hoistway}

The horizontal vibration of the elevator car includes translation in its horizontal direction and rotation about the centroid. When the elevator car deviates from the symmetrical position in the horizontal direction, the lateral force and overturning moment will be generated in the car centroid due to the asymmetric distribution of the airflow on both sides [16]. In order to meet the essential characteristics of high-speed elevator to a greater extent, the paper focus on the high-speed elevator with a car size of $1600 \mathrm{~mm} \times 1600 \mathrm{~mm} \times 2300 \mathrm{~mm}$, a hoistway cross-section of $2000 \mathrm{~mm} \times 2100 \mathrm{~mm}$, and neglects the influence of counterweight and the overall flow of airflow in the hoistway. The hoistway cross-section is assumed to be a rectangle, only the car is considered in the elevator model and the influence of other structures are neglected, then the simplified calculation model of the elevator is set up as shown in Figure 1. The calculation area of the whole flow field is established in the relative coordinate system. The status of the car is considered to be stationary, the speeds of the hoistway wall and airflow are equal to that of the simulated car, and the direction is opposite. The upper and lower surfaces of the hoistway are the air outlet and inlet boundaries respectively. The tetrahedral structured grid is used to mesh the calculated area. The size of the lateral grid around the car is $0.01 \mathrm{~m}$ and the rest is $0.04 \mathrm{~m}$, the size of the longitudinal grid is $0.08 \mathrm{~m}$, and the number of grids is about 520000 .

In this paper, the finite volume method is used to discretize the calculation area of the flow field, and equation (8) is integrated on the control volume. The 


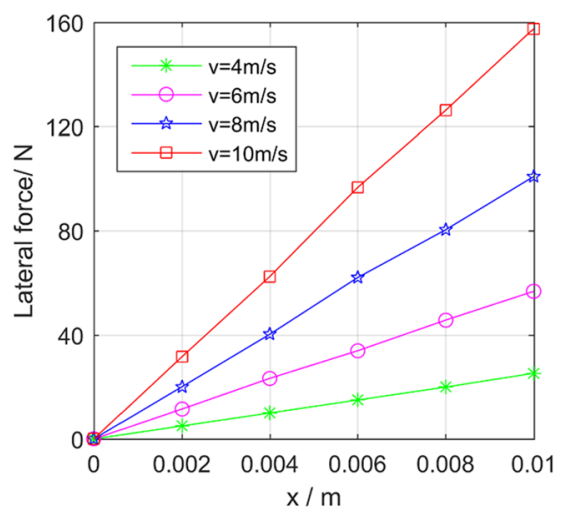

(a) Lateral force generated by horizontal displacement

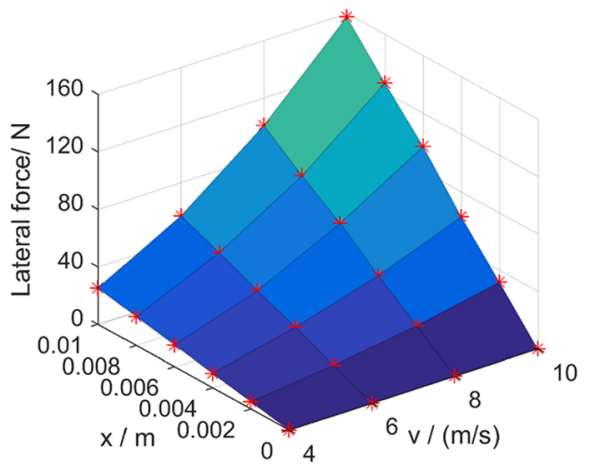

(c) Lateral force at different running speeds and horizontal displacements

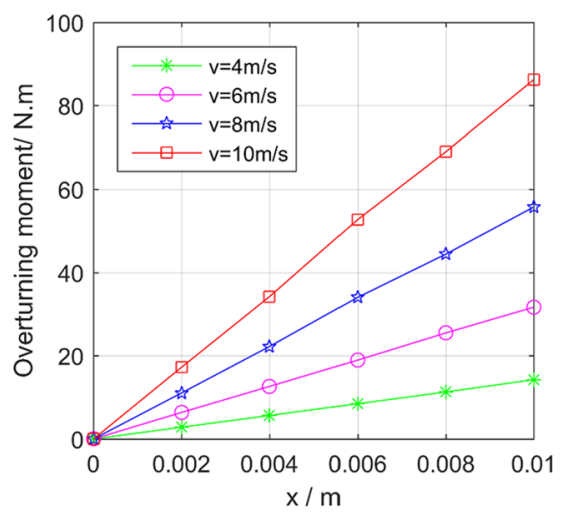

(b) Overturning moment generated by horizontal displacement

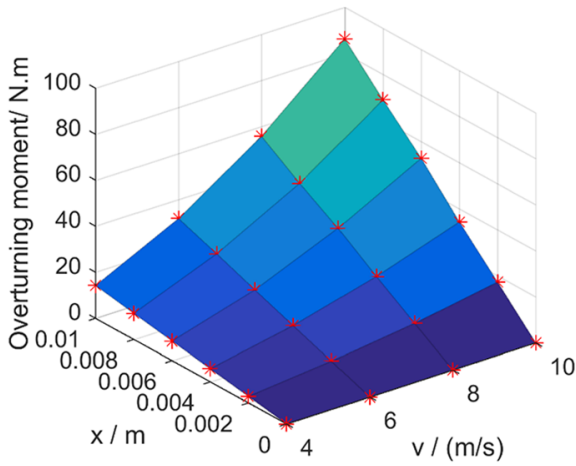

(d) Overturning moment at different running speeds and horizontal displacements

Fig. 2. Lateral force and overturning moment generated by different rated speeds and horizontal displacements.

discrete algebraic equations are generated on the control body nodes by the second-order upwind scheme, and the equations are solved by SIMPLE algorithm of the Fluent solver. The convergence standards for calculating the physical quantities of the flow field are $0.1 \%$. The paper takes the uniform speed stage of high-speed elevator as the research object, simulates the lateral force and overturning moment of the car centroid at different horizontal displacements, deflection angle displacements and rated speeds of the elevator car, and finally studies the relationship of the lateral force and overturning moment with the horizontal displacement, deflection angle displacement and rated speed.

\subsubsection{The influence of car horizontal displacement on the lateral force and overturning moment}

Letting the car horizontal displacement of elevator be $x$ (right is forward direction), the rated speed of elevator car be $v$. In order to ensure the accuracy of the simulation results, in this paper, the car horizontal displacements $(x)$ are taken as $0.002 \mathrm{~m}, 0.004 \mathrm{~m}, 0.006 \mathrm{~m}, 0.008 \mathrm{~m}$ and $0.01 \mathrm{~m}$, which are combined with the rated speeds $(v)$ of $4 \mathrm{~m} / \mathrm{s}, 6 \mathrm{~m} / \mathrm{s}$, $8 \mathrm{~m} / \mathrm{s}$ and $10 \mathrm{~m} / \mathrm{s}$ respectively, and then the effects of the horizontal displacement and rated speed on the lateral force and overturning moment of the car centroid are studied. It is calculated that at the uniform speed stage, the aerodynamic force/moment of the car centroid in a state are certain values, as shown in Figure 2.

It can be seen from Figure 2 that with the increasing of horizontal displacement and rated speed of the car, both the lateral force and overturning moment suffered by the car centroid show an upward trend, and at the same rated speed, the lateral force and overturning moment are direct proportion to the horizontal displacements of the car respectively. Now, we take the ratios of lateral force and overturning moment to horizontal displacement at different rated speeds as the influence coefficients of the horizontal displacement on the lateral force and overturning moment respectively, as shown in Figure 3.

\subsubsection{The influence of car deflection angle displacement on the lateral force and overturning moment}

Letting the car deflection angle displacement be $\theta$ (anticlockwise is the forward direction). In this paper, the car deflection angle displacements $(\theta)$ are $0.5 \pi / 180 \mathrm{rad}$, $\pi / 180 \mathrm{rad}, 1.5 \pi / 180 \mathrm{rad}, 2 \pi / 180 \mathrm{rad}$ and $2.5 \pi / 180 \mathrm{rad}$, which are combined with the rated speeds of $4 \mathrm{~m} / \mathrm{s}, 6 \mathrm{~m} / \mathrm{s}$, $8 \mathrm{~m} / \mathrm{s}, 10 \mathrm{~m} / \mathrm{s}$ and $12 \mathrm{~m} / \mathrm{s}$ respectively, and then we study the effects of the deflection angle displacement and rated speed on the lateral force and overturning moment of the 


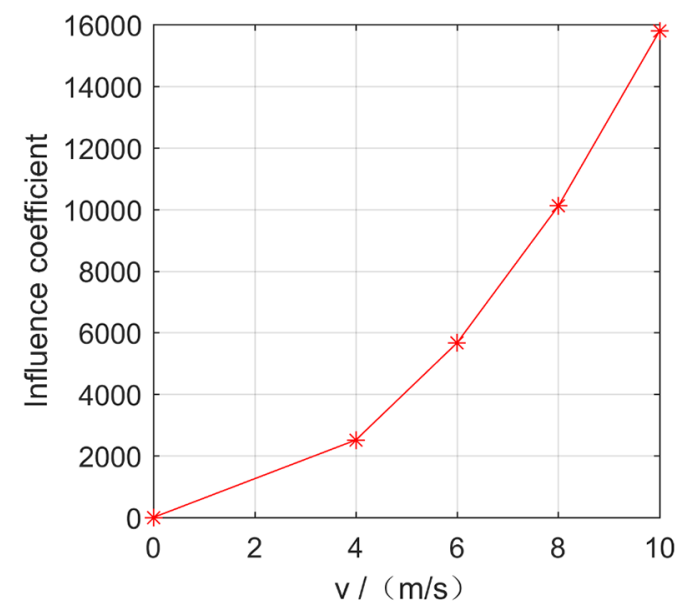

(a) Influence coefficient of horizontal displacement on lateral force

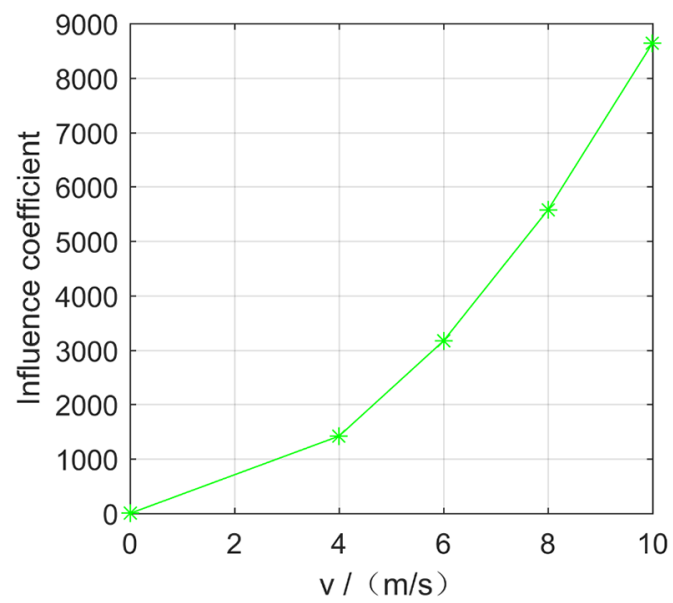

(b) Influence coefficient of horizontal displacement on overturning moment

Fig. 3. Influence coefficients of the horizontal displacement on lateral force and overturning moment at different rated speeds.

car centroid. It is calculated that at the uniform speed stage, the aerodynamic force/moment of the car centroid in a state are certain values, as shown in Figure 4.

As can be seen from Figure 4, both the lateral force and overturning moment suffered by the car centroid also increase linearly with the increasing of deflection angle displacement and rated speed of the car, and at the same speed, the lateral force and overturning moment are direct proportion to the deflection angle displacements respectively. Now, we take the ratios of lateral force and overturning moment to deflection angle displacement at different rated speeds as the influence coefficients of the deflection angle displacement on the lateral force and overturning moment respectively, as shown in Figure 5.

\subsubsection{Solution of lateral force and overturning moment of the car centroid}

From the analysis of Figure 3 and Figure 5, it can be seen that both the horizontal displacement and deflection angle displacement of the car will produce a lateral force and an overturning moment on the car centroid and affect the lateral force and overturning moment to a certain extent. In addition, compared with the car horizontal displacement, the influence of deflection angle displacement on the lateral force and overturning moment is greater. Therefore, according to Figure 3 and Figure 5, combining with the classical theory of aerodynamics, this paper fits the curves of the influence coefficients in Figure 3 and Figure 5 by quadratic curve respectively, and the corresponding expressions that are related to the uniform speed are $C_{f x}=157.9 v^{2}, C_{m x}=86.79 v^{2}, C_{f \theta}=1575 v^{2}$ and $C_{m \theta}=761.6$ $v^{2}$. Because each force/moment has a linear relationship with $x$ and $\theta$ through the corresponding influence coefficients, and the direction of the lateral forces generated by the horizontal displacement and the deflection angle displacement of the car are opposite to the positive direction of the x-axis, so the lateral force $\left(F_{f x}\right)$ and overturning moment $\left(M_{f x}\right)$ acting on the car centroid caused by the horizontal displacement and the lateral force
$\left(F_{f \theta}\right)$ and overturning moment $\left(M_{f \theta}\right)$ acting on the car centroid caused by the deflection angle displacement at different uniform speeds can be written as follows:

$$
\begin{gathered}
F_{f x}=-C_{f x} x=-157.9 v^{2} x \\
M_{f x}=C_{f x} x=86.79 v^{2} x \\
F_{f \theta}=-C_{f \theta} \theta=-1575 v^{2} \theta \\
M_{f \theta}=C_{f \theta} \theta=761.6 v^{2} \theta
\end{gathered}
$$

\section{Analysis of the guiding system excitation}

The final expression form of guide-rail horizontal displacement excitation is the overall straightness deviation, and the rail bending deformation is the most important and common cause of the straightness deviation [17]. Because the main object of this paper is the car horizontal vibration, so we only consider the bending deformation in the onedimensional direction (horizontal direction) when analyzing the guide-rail horizontal displacement excitation. In this paper, the sine wave mode signal is used as the bending deformation deviation, as shown in Figure 6, where $A$ is the amplitude of guide-rail bending deformation, $\Delta L$ is vertical distance between two guide-rail supports.

When the elevator car moves in negative direction of $\mathrm{z}$-axis and with a rated speed of $v$, the excitation at the lower guide-shoe is the same as that at the upper guideshoe, but there is an advanced time that $t_{0}=l / v$, and $l$ is the vertical distance between the upper and lower guideshoes. If the horizontal displacements of the left and right guide-rail at the upper guide-shoe are respectively $x_{d l u}=A_{1} \sin \left(2 \pi f_{r} t\right)$ and $x_{d r u}=B_{1} \sin \left(2 \pi f_{r} t\right)$, then the horizontal displacements of the left and right guide-rail at the lower guide-shoe are $x_{d l d}=A_{1} \sin \left(2 \pi f_{r}\left(t+t_{0}\right)\right)$ and 


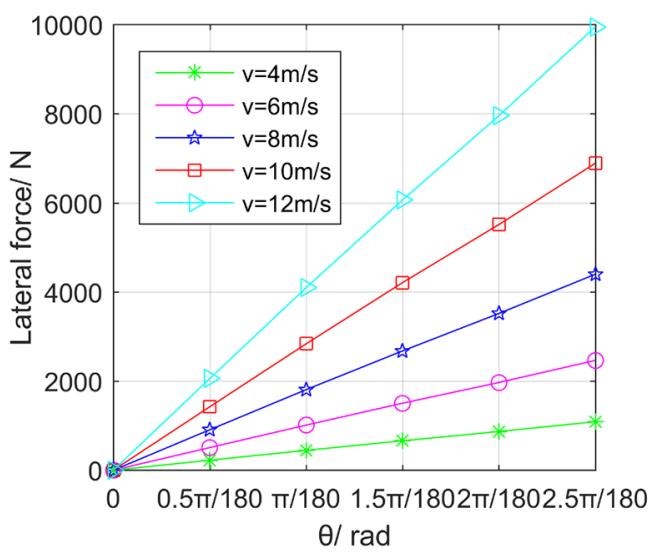

(a) Lateral force generated by deflection angle displacement

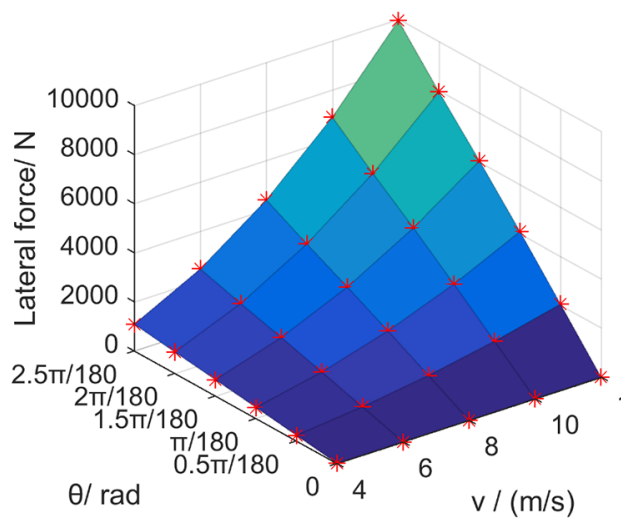

(c) Lateral force at different running speeds and deflection angle displacements

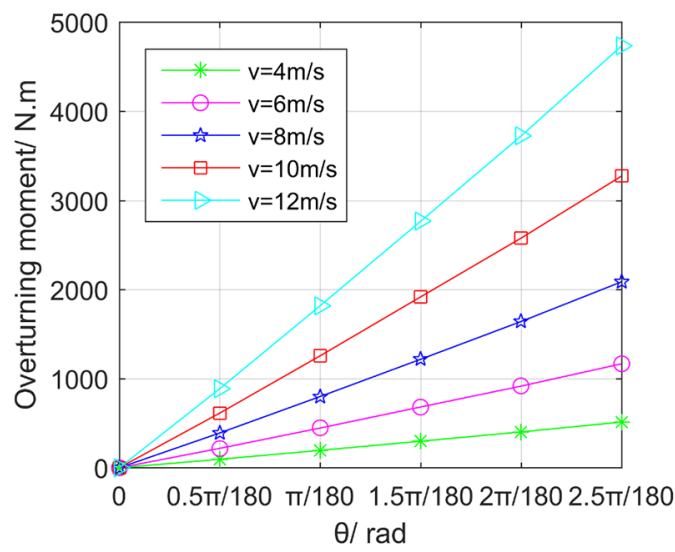

(b) Overturning moment generated by deflection angle displacement

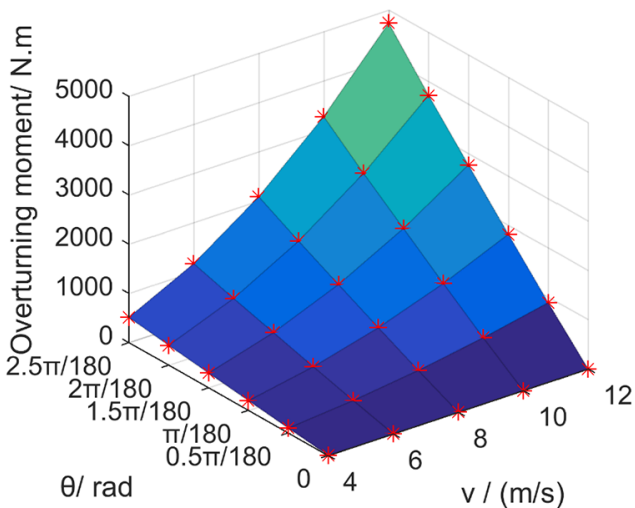

(d) Overturning moment at different running speeds and deflection angle displacements

Fig. 4. Lateral force and overturning moment generated by different rated speeds and deflection angle displacements.

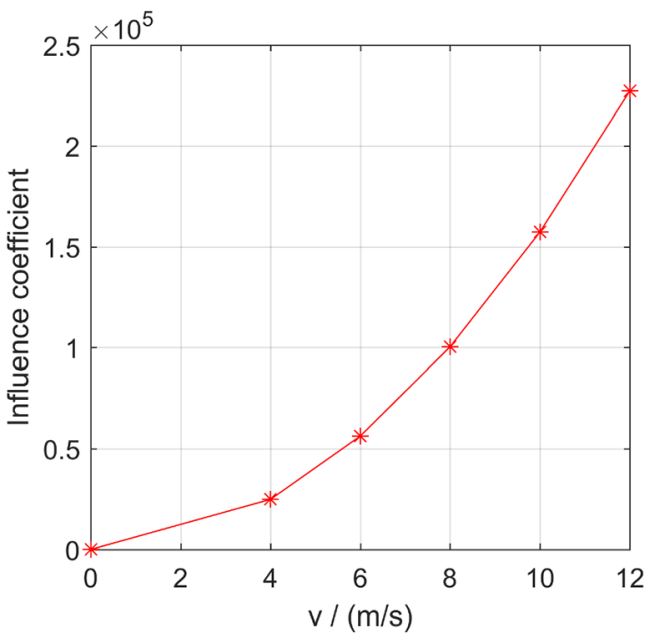

(a) Influence coefficient of deflection angle displacement on lateral force

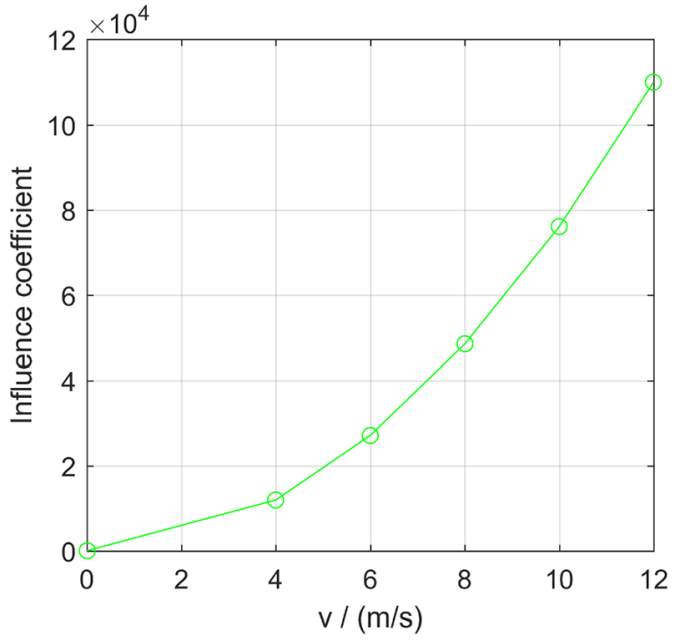

(b) Influence coefficient of deflection angle displacement on overturning moment

Fig. 5. Influence coefficients of the deflection angle displacement on lateral force and overturning moment at different rated speeds. 


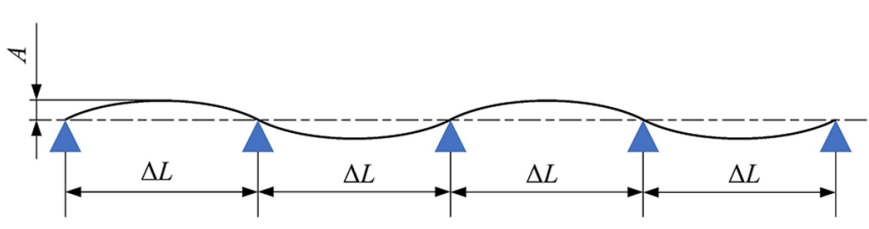

Fig. 6. Bending deformation deviation of guide-rail.

$x_{d r d}=B_{1} \sin \left(2 \pi f_{r}\left(t+t_{0}\right)\right)$, respectively. Where $A_{1}, B_{1}$ are horizontal displacement amplitudes of the left and right guide-rail, $f_{r}$ is guide-rail excitation frequency and $f_{r}=v / \lambda, \lambda$ is wavelength.

In order to avoid the errors caused by the different amplitude and phase of the guide-rails on both sides, the amplitude of guide-rail bending deformation is usually processed by integrating the bending deformation to one side. That is, the bending deformation of one side (left) guide-rail is regarded as a sinusoidal excitation signal, and the other side (right) guide-rail is considered as the ideal rail. That is, $x_{d l u}=A_{1} \sin \left(2 \pi f_{r} t\right), x_{d l d}=A_{1} \sin \left(2 \pi f_{r}\left(t+t_{0}\right)\right)$, $x_{d r u}=0$ and $x_{d r d}=0$.

\section{The dynamic model of the car horizontal vibration under the airflow pressure disturbance and guiding system excitation}

This paper studies the horizontal vibration of high-speed elevator car system, and mainly considers the movement of the car in the horizontal direction and the rotation about the centroid in the plane, depends on the airflow pressure disturbance and guiding system excitation as the external force, simplifies the four guide-wheel and guide-shoe systems as parallel spring-damping systems [18], and finally establishes the horizontal vibration dynamic model of the high-speed elevator car system as shown in Figure 7.

The movement of the elevator car is decomposed into the translation in the horizontal direction and the rotation about the car centroid. Letting car mass be $m_{c}$, car moment of inertia be $I_{c}$, the equivalent stiffness and equivalent damping of the rolling guide-shoe be $k_{e}$ and $c_{e}$, the vertical distances between car centroid and the upper and lower rolling guide-shoe be $h_{1}$ and $h_{2}$, the horizontal force of the guiding system on the car centroid be $F_{f}$ and the moment of the guiding system on the car centroid be $M_{f}$. According to Lagrange equation, the differential equations of high-speed elevator horizontal vibration can be written as follows:

$$
\begin{aligned}
& m_{c} \ddot{x}+4 c_{e} \dot{x}+\left(2 c_{e} h_{2}-2 c_{e} h_{1}\right) \dot{\theta}+4 k_{e} x+\left(2 k_{e} h_{2}\right. \\
& \left.-2 k_{e} h_{1}\right) \theta=\left(k_{e} x_{d l u}+k_{e} x_{d l d}+k_{e} x_{d r u}+k_{e} x_{d r d}\right)+\left(c_{e} \dot{x}_{d l u}\right. \\
& \left.+c_{e} \dot{x}_{d l d}+c_{e} \dot{x}_{d r u}+c_{e} \dot{x}_{d r d}\right)+F_{f x}+F_{f \theta} \\
& I_{c} \theta+\left(2 c_{e} h_{2}-2 c_{e} h_{1}\right) \dot{x}+\left(2 c_{e} h_{1}^{2}+2 c_{e} h_{2}^{2}\right) \dot{\theta} \\
& \quad+\left(2 k_{e} h_{2}-2 k_{e} h_{1}\right) x+\left(2 k_{e} h_{1}^{2}+2 k_{e} h_{2}^{2}\right) \theta \\
& =-\left(k_{e} h_{1} x_{d l u}+c_{e} h_{1} \dot{x}_{d l u}\right)+\left(k_{e} h_{2} x_{d l d}\right. \\
& \left.\quad+c_{e} h_{2} \dot{x}_{d l d}\right)-\left(k_{e} h_{1} x_{d r u}+c_{e} h_{1} \dot{x}_{d r u}\right) \\
& \quad+\left(k_{e} h_{2} x_{d r d}+c_{e} h_{2} \dot{x}_{d r d}\right)+M_{f x}+M_{f \theta}
\end{aligned}
$$

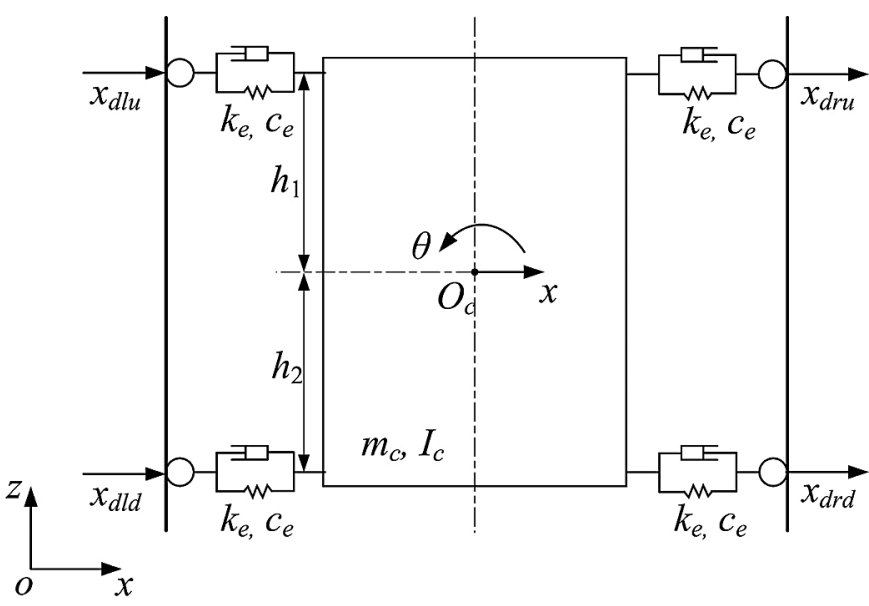

Fig. 7. Dynamic model of horizontal vibration of the system.

Now equations (13) and (14) are converted into the universal form of dynamic equations of the lumped mass system with multiple-degree-of-freedom as follows:

$$
M \ddot{X}+C \dot{X}+K X=F,
$$

with

$$
\begin{aligned}
& \boldsymbol{M}=\operatorname{diag}\left(m_{c}, I_{c}\right), \boldsymbol{K}=\left[\begin{array}{cc}
4 k_{e} & 2 k_{e}\left(h_{2}-h_{1}\right) \\
2 k_{e}\left(h_{2}-h_{1}\right) & 2 k_{e}\left(h_{1}^{2}+h_{2}^{2}\right)
\end{array}\right], \\
& \boldsymbol{X}=[x, \theta]^{\mathrm{T}}, \\
& \dot{\boldsymbol{X}}=[\dot{x}, \theta]^{T}, \boldsymbol{C}=\left[\begin{array}{cc}
4 c_{e} & 2 c_{e}\left(h_{2}-h_{1}\right) \\
2 c_{e}\left(h_{2}-h_{1}\right) & 2 c_{e}\left(h_{1}^{2}+h_{2}^{2}\right)
\end{array}\right], \\
& \ddot{\boldsymbol{X}}=[\ddot{x}, \ddot{\theta}]^{T}, \boldsymbol{F}=\boldsymbol{F}_{1}+\boldsymbol{F}_{2}+\boldsymbol{F}_{3} .
\end{aligned}
$$

where $\boldsymbol{M}$ is mass matrix, $\boldsymbol{C}$ is damping matrix, $\boldsymbol{K}$ is stiffness matrix, $\boldsymbol{F}$ is total excitation matrix acting on the car, $\boldsymbol{F}_{1}$ is guide-rail excitation matrix and,

$$
\begin{gathered}
\boldsymbol{F}_{1}=\left[F_{f}, M_{f}\right]^{T} \\
F_{f}=k_{e}\left(x_{d l u}+x_{d l d}+x_{d r u}+x_{d r d}\right) \\
+c_{e}\left(\dot{x}_{d l u}+\dot{x}_{d l d}+\dot{x}_{d r u}+\dot{x}_{d r d}\right) \\
M_{f}=-h_{1} k_{e}\left(x_{d l u}+x_{d r u}\right)-h_{1} c_{e}\left(\dot{x}_{d l u}+\dot{x}_{d r u}\right) \\
+h_{2} k_{e}\left(x_{d l d}+x_{d r d}\right)+h_{2} c_{e}\left(\dot{x}_{d l d}+\dot{x}_{d r d}\right),
\end{gathered}
$$

$\boldsymbol{F}_{2}$ is airflow excitation matrix caused by horizontal displacement and,

$$
\boldsymbol{F}_{2}=\left[\begin{array}{l}
F_{f x} \\
M_{f x}
\end{array}\right]=\left[\begin{array}{cc}
-157.9 v^{2} & 0 \\
86.79 v^{2} & 0
\end{array}\right]\left[\begin{array}{l}
x \\
\theta
\end{array}\right]
$$

$\boldsymbol{F}_{3}$ is airflow excitation matrix caused by deflection angle displacement and,

$$
\boldsymbol{F}_{3}=\left[\begin{array}{l}
F_{f \theta} \\
M_{f \theta}
\end{array}\right]=\left[\begin{array}{cc}
0 & -1575 v^{2} \\
0 & 761.6 v^{2}
\end{array}\right]\left[\begin{array}{l}
x \\
\theta
\end{array}\right]
$$


Table 1. Parameter values of high-speed elevator system.

\begin{tabular}{llll}
\hline Parameter & Value & Parameter & Value \\
\hline$m_{c} / \mathrm{kg}$ & 900 & $h_{1} / \mathrm{m}$ & 1.15 \\
$\Delta m / \mathrm{kg}$ & 800 & $h_{2} / \mathrm{m}$ & 1.15 \\
$I_{c} /\left(\mathrm{kg} \cdot \mathrm{m}^{2}\right)$ & 1700 & Hoistway & $2.00 \times 2.10$ \\
& & cross-section $/ \mathrm{m}$ & \\
$k_{e} /(\mathrm{N} / \mathrm{m})$ & 154100 & Car & $1.60 \times 1.60$ \\
$c_{e} /(\mathrm{N} \cdot \mathrm{s} / \mathrm{m})$ & 600 & Cross-section $/ \mathrm{m}$ & \\
$L / \mathrm{m}$ & 5.00 & $\Delta L / \mathrm{m}$ & 2.30 \\
\hline
\end{tabular}

\section{Case study}

\subsection{Selection of input parameters}

This paper selects the input parameters referring a type of the high-speed elevators of Shandong Fuji Elevator Co., Ltd., as shown in Table 1 , where $\Delta m$ is car rated load, $L$ is single guide-rail length.

\subsection{Modal analysis of horizontal vibration}

The vibration behavior of a high-speed elevator car belongs to a small damping vibration whose natural frequency can be approximated to the natural frequency of an undamped system. Therefore, the influence of damping and external excitation can be neglected [17]. The characteristic equation and natural frequency of the car system are equations (16) and (17), respectively.

$$
\begin{gathered}
\Delta\left(\omega^{2}\right)=\left|[\boldsymbol{K}]-\omega^{2}[\boldsymbol{M}]\right|=0 \\
f_{n}=\omega / 2 \pi
\end{gathered}
$$

where $\omega$ is natural angular frequency, $f_{n}$ is natural frequency.

Based on equations (16) and (17), we get the first two order natural frequencies of the elevator car under the conditions of no-load, medium-load and full-load, as shown in Table 2. The guide-rail excitation frequency at different rated speeds can be obtained from $f_{r}=v / \lambda=v / 2 \Delta L$, as shown in Table 3.

\subsection{Dynamic response analysis}

Taking $A_{1}=0.8 \times 10^{-3} \mathrm{~m}$ and medium-load condition, for equation (15), we simulate the dynamic response of the car under only the action of the guiding system with different rated speeds and the combined effect of the airflow pressure disturbance and guiding system excitation at different rated speeds based on the Newmark-beta method, respectively. The simulation results are shown in Figure 8.

It can be seen from Figure 8 that the horizontal vibration acceleration response of the car is similar to the horizontal vibration acceleration curve of the car caused
Table 2. Natural frequency of high-speed elevator car $/ \mathrm{Hz}$.

\begin{tabular}{llll}
\hline Order & No-load & Medium-load & Full-load \\
\hline 1 & 4.1651 & 3.4656 & 3.0306 \\
2 & 3.4852 & 3.4852 & 3.4852 \\
\hline
\end{tabular}

Table 3. Guide-rail excitation frequency at different rated speeds.

\begin{tabular}{llllll}
\hline$v /(\mathrm{m} / \mathrm{s})$ & 4 & 6 & 8 & 10 & 12 \\
Frequency $/ \mathrm{Hz}$ & 0.8 & 1.2 & 1.6 & 2.0 & 2.4 \\
\hline
\end{tabular}

by the sinusoidal guide-rail displacement excitation in reference [19]. And the former part of each vibration acceleration curve is the coexistence stage of damped vibration and forced vibration, and the latter part is the stage where only the forced vibration exists. Besides, the damped vibration frequency is equal to the first natural frequency of the system theoretically. From Figure 8, we can see that the damped vibration frequency is about $3.5 \mathrm{~Hz}$ (the cyclic number of damped vibration per second is about 3.5), which is very close to $3.4656 \mathrm{~Hz}$ in Table 2 (a certain amount of error is caused by the system model assumptions and so on), which verifies the correctness of the model and numerical calculation method used in this paper. From the analysis of Figure 8, we can obtain the single-peak values of the car horizontal vibration acceleration with different rated speeds with or without considering the influence of airflow pressure disturbance, as shown in Table 4 and Figure 9.

\subsection{Results and discussion}

From Table 2, it can be seen that the natural frequencies of the car horizontal vibration are between 3 and $4.2 \mathrm{~Hz}$. When the car is no-loaded, medium-loaded and full-loaded, the first natural frequency shows a slight decrease trend; the second natural frequency is invariant. In addition, through the contrast analysis between Tables 2 and 3, we can know that with the increase of the elevator car rated speed, the guide-rail excitation frequency is getting closer to the car natural frequency within a certain range, that is, the higher the speed is, the more obvious the resonance phenomenon between the guide-rail and the car system will be.

As can be seen from Table 4 and Figure 9, the singlepeak value of the car horizontal acceleration is getting larger and larger with the increasing of rated speed. And when the speed is less than $6 \mathrm{~m} / \mathrm{s}$, the single-peak value considering the airflow pressure disturbance shows an increasing trend compared with no-consideration on the airflow pressure disturbance, but the variation is very small; while when the speed is greater than $6 \mathrm{~m} / \mathrm{s}$, compared to the no-consideration on the airflow pressure disturbance, the single-peak value is increased at a rate of 

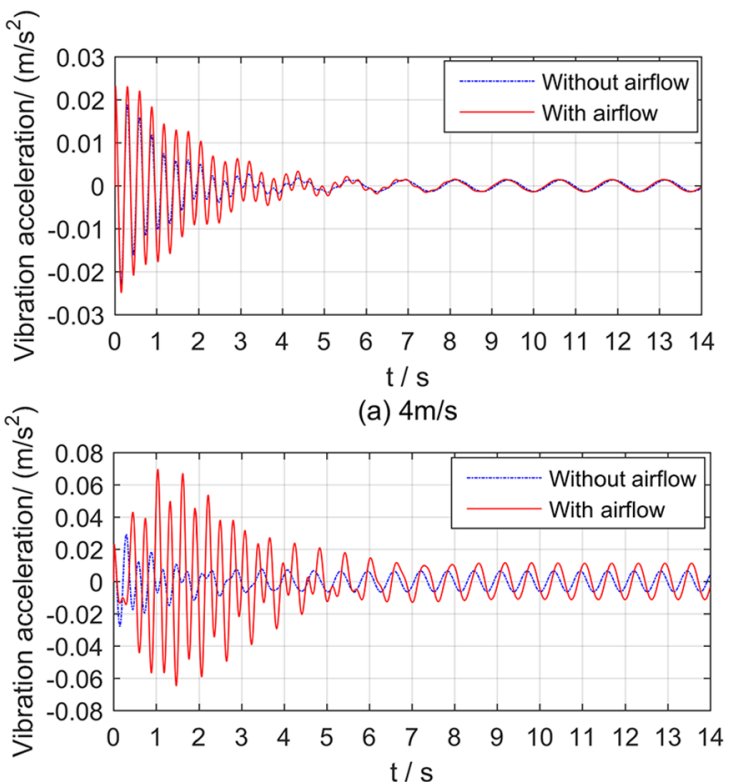

(c) $8 \mathrm{~m} / \mathrm{s}$

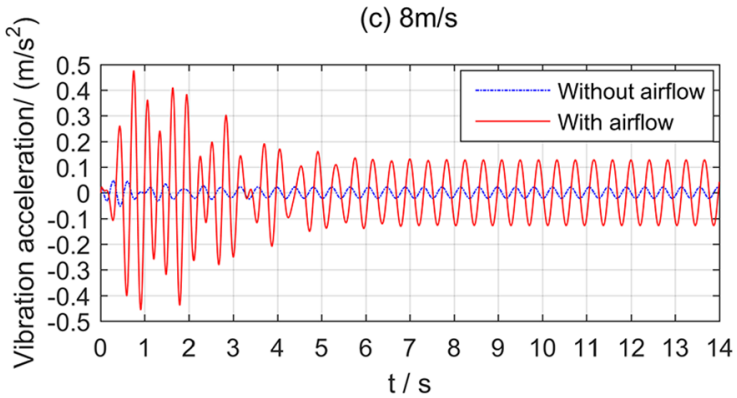

(e) $12 \mathrm{~m} / \mathrm{s}$

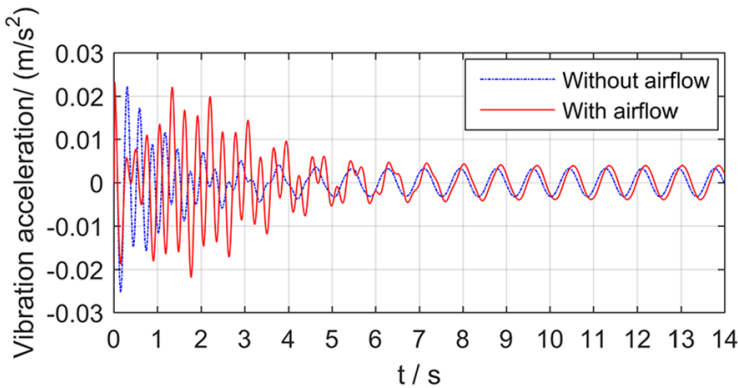

(b) $6 \mathrm{~m} / \mathrm{s}$

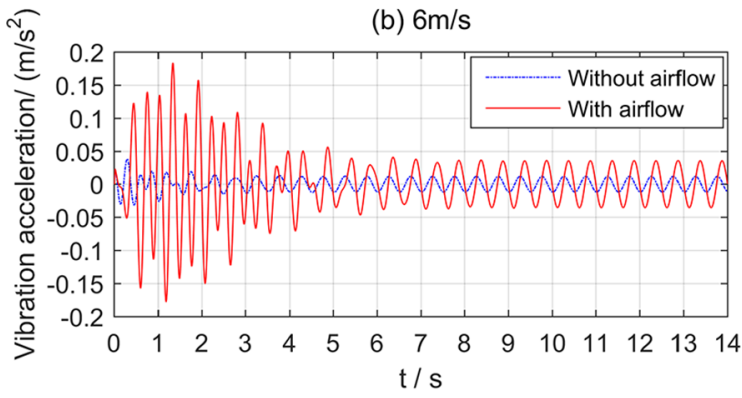

(d) $10 \mathrm{~m} / \mathrm{s}$

Fig. 8. Horizontal vibration acceleration of elevator car at different rated speeds.

Table 4. Single-peak value of horizontal vibration acceleration $/\left(\mathrm{m} / \mathrm{s}^{2}\right)$.

\begin{tabular}{llllll}
\hline Working & 4 & 6 & 8 & 10 & 12 \\
conditions & $\mathrm{m} / \mathrm{s}$ & $\mathrm{m} / \mathrm{s}$ & $\mathrm{m} / \mathrm{s}$ & $\mathrm{m} / \mathrm{s}$ & $\mathrm{m} / \mathrm{s}$ \\
\hline Without airflow & 0.0014 & 0.0032 & 0.0065 & 0.0119 & 0.0220 \\
With airflow & 0.0016 & 0.0043 & 0.0118 & 0.0365 & 0.1283 \\
\hline
\end{tabular}

quadratic when considering the flow pressure disturbance. And according to the analysis of Section 2.2, it can be seen that the faster the elevator car rated speed, the more obvious the effect of deflection angle displacement on the horizontal vibration acceleration of elevator car.

\section{Concluding remarks}

Aiming at the two main excitation sources of horizontal vibration for high-speed elevator - the airflow pressure disturbance and guiding system excitation, through the numerical analysis of 3-D calculation model of high-speed

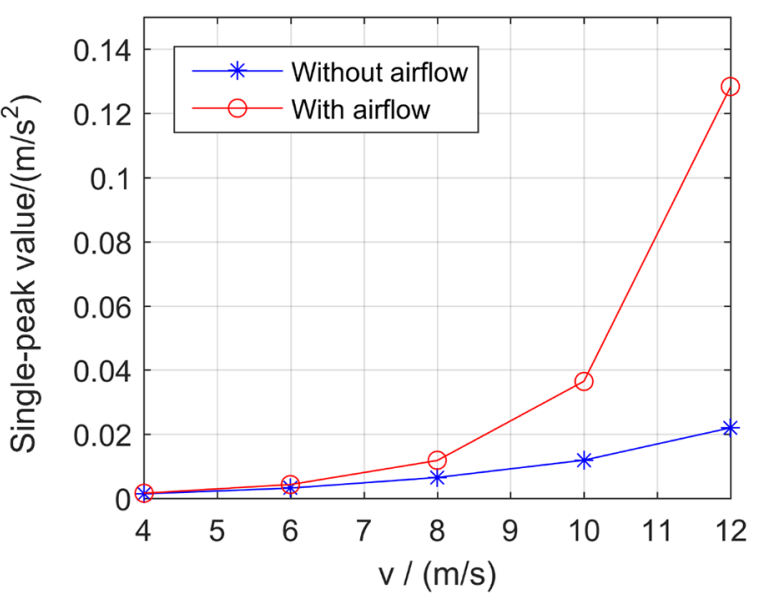

Fig. 9. Single-peak value of horizontal vibration acceleration at different rated speeds.

elevator system, this paper studies the relationship of the lateral force and the overturning moment acting on the car centroid with the horizontal displacement, deflection angle displacement and rated speed respectively. The effect of horizontal displacement and deflection angle displacement 
cannot be neglected, and finally establishes a horizontal vibration dynamics model under the combined action of above two main excitation sources.

In this paper, by analyzing the influence coefficients of horizontal displacement and deflection angle displacement on the lateral force and overturning moment of the car respectively, we conclude that the effect of the deflection angle displacement on the lateral force and the overturning moment is more obvious under the constraint of the guiderails on both sides. Therefore, in the study of horizontal vibration control of high-speed elevator, the control of deflection angle displacement should be taken as the main point.

Through the study of natural frequency and dynamic response of horizontal vibration with and without the consideration of the airflow pressure disturbance under the same guiding system excitation, we conclude that in a certain range, the higher the rated speed is, the more obvious the resonance phenomenon between the guide-rail and car will be; when the elevator car under no-load, medium-load and full-load condition, the first natural frequency shows a trend of slight decrease, while the second natural frequency is invariant; for the elevator with rated speed less than $6 \mathrm{~m} / \mathrm{s}$, the influence of airflow pressure disturbance on the single-peak value of horizontal vibration acceleration is negligible; however, when the rated speed is over $6 \mathrm{~m} / \mathrm{s}$, the influence of airflow pressure disturbance on the single-peak value is approximately a rate of quadratic ratio relationship, and with the increasing rated speed, the influence of deflection angle displacement on the horizontal vibration acceleration is more and more obvious. Therefore, the influence of airflow should not be ignored in the study of horizontal vibration. The above conclusions have some theoretical significance in the research on the horizontal vibration characteristics and control of high-speed elevator.

\section{Nomenclature}

$A$

$A_{1}$

$B_{1}$

C

$C_{f x}, C_{m x}, C_{f \theta}, C_{m \theta}$

$C_{\mu}, C_{1}, C_{2}, \sigma_{k}, \sigma_{\varepsilon}$

$c_{e}$

div

F

$\boldsymbol{F}_{1}$
$\boldsymbol{F}_{2}$

$\boldsymbol{F}_{3}$

$F_{f}$
$F_{f x}$

$F_{f \theta}$

$f_{n}$

$f_{r}$

$\operatorname{grad}$

$h_{1}$

$h_{2}$

$I_{c}$
$\boldsymbol{K}$

$k$

$k_{e}$

$L$

$l$

$M$

$\mathrm{Ma}$

$M_{f}$

$M_{f x}$

$M_{f \theta}$

$m_{c}$

$p$
$\mathrm{Re}$

$\mathrm{Re}$

$S \varphi$

$t$

$t_{0}$

$\boldsymbol{U}$

$u_{a}, v_{a}, w_{a}$

$v$

$x$

$x_{d l u}$

Amplitude of guide-rail bending deformation (m)

Horizontal displacement amplitude of left guide-rail (m)

Horizontal displacement amplitude of right guide-rail (m)

Damping matrix

Influence coefficient

Empirical constant

Equivalent damping of rolling guideshoe (N.s.m ${ }^{-1}$ )

Divergence

Total excitation matrix acting on the car

Guide-rail excitation matrix

Airflow excitation matrix caused by horizontal displacement

Airflow excitation matrix caused by deflection angle displacement

Horizontal force of guiding system on car centroid (N)
Lateral force caused by horizontal displacement $(\mathrm{N})$

Lateral force caused by deflection angle displacement $(\mathrm{N})$

Car natural frequency $(\mathrm{Hz})$

Guide-rail excitation frequency $(\mathrm{Hz})$

Gradient

Vertical distance between car centroid and upper guide-shoe $(\mathrm{m})$

Vertical distance between car centroid and lower guide-shoe (m)

Car moment of inertia $\left(\mathrm{kg} \cdot \mathrm{m}^{-2}\right)$

Stiffness matrix

Turbulent kinetic energy $(\mathrm{J})$

Equivalent stiffness of rolling guide-shoe $\left(\right.$ N.m ${ }^{-1}$ )

Single guide-rail length (m)

Vertical distance between upper and lower guide-shoes (m)

Mass matrix

Mach number

Moment of guiding system on car centroid (N.m)

Overturning moment caused by horizontal displacement (N.m)

Overturning moment caused by deflection angle displacement (N.m)

Car mass (kg)

Pressure (Pa)

Reynolds number

Generalized source term

Time (s)

Advanced time between upper and lower guide-shoes (s)

Air velocity vector

Velocity component of $\boldsymbol{U}$ in $\mathrm{x}, \mathrm{y}, \mathrm{z}$ coordinate directions $\left(\mathrm{m} . \mathrm{s}^{-1}\right)$

Car-rated speed (m.s $\left.{ }^{-1}\right)$

Car horizontal displacement (m)

Horizontal displacement of left guiderail at upper guide-shoe (m)

Horizontal displacement of right guiderail at upper guide-shoe (m)

Horizontal displacement of left guiderail at lower guide-shoe (m)

Horizontal displacement of right guiderail at lower guide-shoe (m)

Car deflection angle displacement (rad)

Air density (kg.m $\left.{ }^{-3}\right)$

Air kinematic viscosity $\left(\mathrm{m}^{-2} \cdot \mathrm{s}^{-1}\right)$

Turbulent dissipation rate

Air dynamic viscosity (N.s.m ${ }^{-2}$ )

Turbulent viscosity coefficient (N.s.m ${ }^{-2}$ )

Generic variable

Generalized diffusion coefficient

Vertical distance between two guide-rail supports $(\mathrm{m})$

Elevator-rated load (kg)

Wavelength (m)

Natural angular frequency $(\mathrm{Hz})$ 
Acknowledgments. The authors are grateful for the financial support by Shandong Provincial Natural Science Foundation, China (ZR2017MEE049) and the Introduction of Urgently Needed Talents for Economic Rising Zone in Western China and the Key Areas for Poverty Alleviation and Development in Shandong Province in 2017.

\section{References}

[1] N. Mutoh, K. Kagomiya, T. Kurosawa, M. Konya, T. Andoh, Horizontal vibration suppression method suitable for super-high-speed elevators, Elect. Eng. Japan 129 (2015) 59-73

[2] W.J. Fu, C.M. Zhu, C.Y. Zhang, Modeling and simulation for dynamics of single wrapped elevator, Acta Simulata Syst. Sin. 17 (2005) 635-638

[3] Z.C. Cao, The theory and experiment research of high-speed elevators vibration characteristics, Thesis, Central South University, 2012

[4] T.F. Xie, Z.Y. Liu, W. Chen, Z.W. Liu, Y.T. Wang, Control method for lateral vibration of super high speed elevator's cabin, Hoist. Convey. Mach. 10 (2010) 77-79

[5] B.H. Xia, X. Shi, Horizontal vibrations of high-speed elevator with guide rail excitation, Mach. Build. Automation 41 (2012) 161-165

[6] J.C. Yin, Y.N. Rui, L.M. Jiang, B. Huang, Y.B. Li, Research on high-speed elevator MDOF horizontal dynamic characteristics and simulation, J. Mach. Design 28 (2011) 70-73

[7] D.Q. Mei, X.Q. Du, Z.C. Chen, Vibration analysis of highspeed traction elevator based on guide roller-rail contact model, J. Mech. Eng. 45 (2009) 264-270

[8] K. Utsunomiya, K.I. Okamoto, T. Yumura, K. Funai, H. Kuraoka, Active roller guide system for high-speed elevators, Elevator World 50 (2002) 86-92

[9] D. Colón, A. Cunha, S. Kaczmarczyk, J.M. Balthazar, On dynamic analysis and control of an elevator system using polynomial chaos and Karhunen-Loève approaches, Proc. Eng. 199 (2017) 1629-1634

[10] Y. Duan, G.X. Shen, Y.G. Zhang, W.B. Su, Aerodynamic testing simulation facility for high speed elevator, J. Beijing Univ. Aero. Astro. 30 (2004) 444-447

[11] H.L. Bai, G.X. Shen, A. So, Experimental-based study of the aerodynamics of super-high-speed elevators, Build. Serv. Eng. Res. Technol. 26 (2005) 129-143

[12] X.B. Wang, Z. Lin, P. Tang, Z.W. Ling, Research of the blockage ratio on the aerodynamic performances of high speed elevator, in: 4th International Conference on Mechatronics, Materials, Chemistry and Computer Engineering, Xi'an, China, 2015, pp. 2357-2361

[13] X.D. Li, K. Wang, Optimization of aerodynamic characteristics of high-speed elevator, J. Harbin Inst. Technol. 41 (2009) 82-86

[14] L.Q. Shi, Y.Z. Liu, S.Y. Jin, Z.M. Cao, Numerical simulation of unsteady turbulent flow induced by two-dimensional elevator car and counter weight system, J. Hydrodynam. 19 (2007) 720-725

[15] D.D. Chen, Aerodynamic characteristic of the super highspeed elevator base on different hoistway models, Mech. Elect. Eng. Magazine 33 (2016) 1359-1363

[16] H.J. Du, Study on the influence of aerodynamic force on the dynamic characteristics of high-speed elevator system, Thesis, Soochow University, 2009

[17] J. Chen, Performance analysis of horizontal vibration in high-speed elevator and design optimization of guidance system and its application, Thesis, Zhejiang University, 2016

[18] C. Wang, R.J. Zhang, Q. Zhang, Analysis of transverse vibration acceleration for a high-speed elevator with random parameter based on perturbation theory, Int. J. Acoustics Vibration 22 (2017) 218-223

[19] W.J. Fu, C.M. Zhu, C.Y. Zhang, Q.T. Ye, Modeling and analyzing lateral vibration for high-speed elevators, Mach. Design Res. 19 (2003) 65-67

Cite this article as: J. Liu, R. Zhang, Q. He, Q. Zhang, Study on horizontal vibration characteristics of high-speed elevator with airflow pressure disturbance and guiding system excitation, Mechanics \& Industry 20, 305 (2019) 